\title{
A GESTÃo DE RESÍDUOS, AS POLÍTICAS PÚBLICAS E O AGRONEGÓCIO COMO CONTRIBUIÇÕES PARA O DESENVOLVIMENTO
}

Anderson Catapan ${ }^{1}$, Editor-chefe

\section{RESUMO}

Este editorial introduz o segundo número do quarto volume da Revista Brasileira de Planejamento e Desenvolvimento. Os tópicos dos artigos incluem gestão de resíduos sólidos, políticas públicas na saúde, auditoria, bionegócios, obras geotécnicas, contratos do agronegócio, inovação em tecnologia de transporte, princípios de processo administrativo e planejamento regional.

Palavras-chave: Gestão de resíduos sólidos, políticas públicas na saúde, inovação, planejamento regional.

\section{Editorial}

Este editorial introduz o segundo número do quarto volume da Revista Brasileira de Planejamento e Desenvolvimento (RBPD). Estamos fechando o quarto ano da revista e, neste sentindo, aproveitamos para apresentar algumas conquistas recentes: indexação, até o momento, em 11 bases de dados (entre elas Latindex, Dialnet); internacionalização do conselho editorial, com a presença de professores do Brasil, Portugal, França, Argentina, Paraguai, México, Colômbia, Venezuela, Equador, entre outros países; internacionalização nos autores que publicam na revista, com autores de Portugal, Colômbia, Argentina, México, entre outros.

Em relação à temática, este número traz, no primeiro artigo, uma discussão de Freitas, Martins e Oliveira (2015) sobre a gestão de resíduos sólidos municipais no contexto de Portugal. Em seguida, Vasconcelos, Silva e Rotta (2015) apresentam uma contribuição sobre políticas públicas na saúde no município de Curitiba.

Ospina e Cortés (2015), na terceira pesquisa apresentada, trazem uma proposta de guia metodológica para auditar o Estado, no contexto da Controladoria Geral de Antioquia. Wandscheer (2015) trabalha com desenvolvimento de bionegócios no próximo artigo. Depois, Miranda e Martins (2015) abordam as políticas públicas na conjuntura do desenvolvimento rural.

Rios (2015) discute, em seguida, a aplicação de uma calculadora de carbono para obra geotécnicas. Rocha Jr., Bittencourt e Ribeiro (2015) abordam, depois, as características dos contratos no agronegócio do Brasil. Botache (2015) trata da inovação com tecnologia de transporte em massa no contexto de Bogotá.

Ainda, Cury-Mendes (2015) trata dos princípios do processo administrativo federal e a formalidade dos atos processuais como contribuições para o desenvolvimento. Fechamos este número com a contribuição de Rosa, Rocha e Marimon (2015), trazendo considerações sobre a proposta de planejamento regional no extremo sul de Santa Catarina.

\footnotetext{
${ }^{1}$ Departamento Acadêmico de Gestão e Economia, Universidade Tecnológica Federal do Paraná, Curitiba, Brasil.

E-mail: catapan@utfpr.edu.br
} 
Assim, esperamos que todos tenham uma ótima leitura, e que as contribuições aqui apresentadas sejam relevantes para o desenvolvimento da temática desta área a nível nacional e internacional!

\section{Referências}

BOTACHE, D. M. La innovaciòn con tecnologías en el sistema de transporte masivo e integrado urbano Bogotá - Soacha y su impacto en el desarrollo territorial sustentable. Revista Brasileira de Planejamento e Desenvolvimento, v. 4, n. 2, p. 119-131, 2015.

CURY-MENDES, C. C. Princípios do processo administrativo federal e a formalidade dos atos processuais: Uma discussão com foco no desenvolvimento. Revista Brasileira de Planejamento e Desenvolvimento, v. 4, n. 2, p. 132-147, 2015.

FREITAS, A. L. M.; MARTINS, F. V.; OLIVEIRA, E. R. Determinants of municipal solid waste management in Portugal. Revista Brasileira de Planejamento e Desenvolvimento, v. 4, n. 2, p. 3-10, 2015.

MIRANDA, D. L. R.; MARTINS, P. As políticas públicas na conjuntura do desenvolvimento rural e manutenção da agricultura familiar: Paradigmas, desafios e controvérsias. Revista Brasileira de Planejamento e Desenvolvimento, v. 4, n. 2, p. 69-83, 2015.

OSPINA, N. E. G.; CORTÉS, E. M. G. Propuesta de Guía Metodológica para auditar el estado de las Tecnologías de Información y las Telecomunicaciones - TIC - en las entidades públicas que fiscaliza la Contraloría General de Antioquia (Colombia). Revista Brasileira de Planejamento e Desenvolvimento, v. 4, n. 2, p. 33-49, 2015.

RIOS, S. Application of a recently developed geotechnical carbon calculator in Europe. Revista Brasileira de Planejamento e Desenvolvimento, v. 4, n. 2, p. 84-93, 2015.

ROCHA Jr.; W. F.; BITTENCOURT, M. V. L.; RIBEIRO, M. C. P. Análise das características dos contratos no agronegócio do Brasil. Revista Brasileira de Planejamento e Desenvolvimento, v. 4, n. 2, p. 94-118, 2015.

ROSA, T. D.; ROCHA, I. O.; MARIMON, M. P. C. Considerações sobre a proposta de planejamento regional no extremo sul de Santa Catarina: Projeto geoparque caminhos dos cânions do sul. Revista Brasileira de Planejamento e Desenvolvimento, v. 4, n. 2, p. 148-167, 2015.

VASCONCELOS, M. C.; SILVA, C. L.; ROTTA, C. V. Políticas públicas em saúde, sistema único de saúde e o papel do legislativo municipal: Um estudo sobre os projetos de Lei Ordinária na área da saúde da cidade de Curitiba no período 2008-2011. Revista Brasileira de Planejamento e Desenvolvimento, v. 4, n. 2, p. 11-32, 2015.

WANDSCHEER, C. B. Desenvolvimento de bionegócios e conhecimento tradicional: uma análise de suas influências nas populações tradicionais no Brasil. Revista Brasileira de Planejamento e Desenvolvimento, v. 4, n. 2, p. 50-68, 2015. 